\title{
Líquens e outros organismos epifílicos em Conchocarpus macrophyllus J.C. Mikan no Parque Estadual do Rio Doce, Minas Gerais, Brasil
}

\author{
JULIO ANTONIO LOMBARDI ${ }^{1,2,3}$, ALEXANDRE SALINO ${ }^{1}$, FLÁVIA REGINA NASCIMENTO \\ TOLEDO $^{1}$ e MÁRCIA SOLANGE MARQUES ${ }^{1}$
}

(recebido em 01/12/98; aceito em 29/09/99)

\begin{abstract}
Lichens and other epiphyllous organisms on Conchocarpus macrophyllus J.C. Mikan in the Parque Estadual do Rio Doce, Minas Gerais, Brazil). Epiphyllous organisms on C. macrophyllus were found in two plots examined in July 1996, in two areas with different fire disturbance intensity, in the Parque Estadual do Rio Doce, MG. Fourteen epiphyllous species were found including: 11 lichens, one alga, one hepatica and one fungus. Lichens accounted for $81.8 \%$ of the epiphyllous species found in the less disturbed area and $72.7 \%$ in the other one. The most abundant species was Porina epiphylla, found in $80.8 \%$ of phorophytes in the former area, and $97 \%$ in the latter. The number of epiphyllous covered leaves per phorophyte, the coverage in each leaf, and the height of the phorophytes were significantly different for both areas, whereas the leaf area and the number of leaves per phorophyte were not. Although no significant differences were found in the epiphyllous specific composition between both areas, the highest occurrence of epiphylls could be associated with disturbance events. The intensified light penetration caused by gaps in the disturbed forest may have enhanced the phorophyte height growth and the colonization of leaves by epiphylls.
\end{abstract}

RESUMO - (Líquens e outros organismos epifílicos em Conchocarpus macrophyllus J.C. Mikan no Parque Estadual do Rio Doce, Minas Gerais, Brasil). Organismos epifílicos em C. macrophyllus foram encontrados em duas parcelas amostradas em julho de 1996, em duas áreas com diferentes graus de perturbação pelo fogo, no Parque Estadual do Rio Doce, MG. Quatorze espécies epifílicas foram encontradas incluindo: 11 líquens, uma alga, uma hepática e um fungo. Os líquens totalizaram $81,8 \%$ das espécies na área menos perturbada e $72,7 \%$ na mais perturbada. A espécie mais abundante foi Porina epiphylla, que ocorreu em $80,8 \%$ dos forófitos da primeira área e em $97 \%$ dos forófitos da segunda. O número de folhas cobertas em cada forófito, o grau de cobertura em cada folha e a altura dos forófitos foram significativamente diferentes entre as duas áreas, enquanto que a área foliar e o número de folhas por forófito não o foram. Embora diferenças significativas não tenham sido encontradas na composição específica do epifilo entre as duas áreas, a maior ocorrência de folhas cobertas pelo epifilo pode estar associada à perturbação. A penetração de luz, intensificada pelas clareiras, pode ter aumentado o crescimento em altura do forófito e a colonização das folhas pelos organismos epifílicos.

Key words - Lichens, epiphyllous organisms, Conchocarpus macrophyllus, Parque Estadual do Rio Doce

\section{Introdução}

Organismos epifílicos são aqueles que crescem sobre a superfície das folhas vivas de plantas vasculares. Nas regiões tropicais úmidas, várias espécies de líquens, musgos e hepáticas fixam-se sobre as folhas das plantas como epifilo (Lücking 1995), além de fungos e algumas algas (Andreoli \& Paoletti 1993).

Alguns líquens epifílicos são importantes fixadores de nitrogênio, que pode então ser absorvido pelo forófito (Bentley \& Carpenter 1984, Benzing 1990, Lessica et al. 1991), enquanto outros podem chegar a causar danos aos hospedeiros, como é o caso de algumas espécies que liberam fitotoxinas (Benzing 1990).

1. Departamento de Botânica, Instituto de Ciências Biológicas, Universidade Federal de Minas Gerais, Av. Antônio Carlos 6627, 31270-110 Belo Horizonte, MG, Brasil.

2. Bolsa de Produtividade em Pesquisa - CNPq.

3. Autor para correspondência: julioicb@dedalus.lcc.ufmg.br
A diversidade de líquens epifílicos é maior na região neotropical, onde existem cerca de 350 espécies, com registros superiores a 200 espécies em um único local de coleta (Lücking 1997a) e com até 68 espécies encontradas em uma única folha (Lücking 1995). Considera-se que o número de espécies de líquens epifílicos é menor em florestas montanas, em vegetação perturbada ou secundária e em florestas semidecíduas ou áreas secas, onde são quase ausentes (Lessica et al. 1991, Lücking 1995, 1997a, b).

Folhas das árvores das florestas úmidas são habitats de período de vida relativamente curto e ocupados por um grupo de líquens especializados que possuem pequeno tamanho e altas taxas de crescimento (Rogers 1989). Considerando-se uma única folha, o número de espécies aumenta com a idade e, então, lentamente decresce até logo antes da queda da folha. A idade de folhas com máxima diversidade depende da espécie do forófito, mas está comumente entre 24 e 32 meses (Lücking 1995). 
Várias espécies de líquens epifílicos são também consideradas como excelentes bioindicadoras de perturbação antropogênica e microclima, pois a composição da flora epifílica é extremamente sensível a flutuações da intensidade luminosa, embora menos úteis como indicadores de zonação altitudinal e sazonalidade (Lücking 1997b). Apesar do número de espécies decrescer em florestas secundárias, florestas montanas e áreas secas, algumas espécies são apenas encontradas em áreas de vegetação impactada, provavelmente pela maior exposição à luz (Lücking 1995).

Embora normalmente encontrados em ampla variação de altitude, de microambientes e de forófitos, algumas espécies de líquens epifílicos são conhecidas apenas para uma espécie de suporte. A preferência por habitats específicos está mais relacionada a líquens não-epifílicos do que aos epifílicos. Grande número de espécies de líquens epifílicos usualmente coexistem em uma única folha, sendo consideradas ecologicamente equivalentes, visto que as variações de distribuição são atribuídas à dispersão ao acaso dos diásporos (Wolf 1994, Lücking 1995).

As variações de habitat acarretam as maiores diferenciações entre populações de líquens epifílicos. Por isso, o dossel de uma floresta apresenta vegetação epifílica muito diferente daquela encontrada no seu sub-bosque. Nas áreas de borda, espécies de ambos, dossel e sub-bosque, podem coexistir pois a ampla variação na intensidade de luz permite o seu estabelecimento (Lücking 1995).

No Brasil, apesar dos líquens epifílicos serem considerados bem conhecidos taxonomicamente (Lücking 1997a), não há levantamentos florísticos de áreas específicas, sendo esses organismos normalmente ignorados nos levantamentos da diversidade vegetal que compreende, na maior parte das vezes, plantas vasculares.

Este estudo teve como objetivo inventariar os organismos epifílicos presentes em Conchocarpus macrophyllus J.C. Mikan e comparar a freqüência e ocorrência das espécies em duas áreas de mata atlântica com diferentes graus de perturbação.

\section{Material e métodos}

Este estudo foi realizado no Parque Estadual do Rio Doce (PERD), que é atualmente o maior remanescente de floresta atlântica no estado de Minas Gerais. O PERD compreende uma área de 35973 ha em um mosaico de matas primárias e secundá- rias, situado entre $19^{\circ} 48^{\prime}-19^{\circ} 30^{\prime} \mathrm{S}$ e $42^{\circ} 38^{\prime}-42^{\circ} 28^{\prime} \mathrm{W}$ (figura 1). Foi estabelecido como área de preservação em 1944 e abrange três municípios, Marliéria, Timóteo e Dionísio (Bruck et al. 1995). A vegetação do PERD é classificada como Floresta Estacional Semidecidual, dentro do domínio da floresta atlântica brasileira (IBGE 1992). Apresenta clima sazonal, tendo um período seco com temperaturas médias mensais de 15 a $20^{\circ} \mathrm{C}$, de abril a setembro, e um período chuvoso com temperaturas de 20 a $22^{\circ} \mathrm{C}$, de outubro a março (CETEC 1981). No município de Dionísio, em área adjacente ao Parque, a precipitação média anual registrada é de 1450 mm (Silva Jr. et al. 1995).

As áreas amostradas foram duas trilhas dentro dos limites do Parque: Campolina e Vinhático (figura 1). A primeira é considerada como representante de mata primária, não tendo sofrido ação do fogo há mais de 50 anos, enquanto a segunda foi queimada há cerca de 30 anos atrás e, atualmente, é utilizada como trilha para demonstração da vegetação para visitantes.

As duas áreas apresentam populações de Conchocarpus macrophyllus (Rutaceae), um arbusto que ocorre no sub-bosque e possui folhas simples e alternas, coriáceas, longo-pecioladas, inteiras, variando de elípticas a obovais. As populações constituem-se em agrupamentos de número variável de indivíduos formando manchas conspícuas por entre a vegetação arbustivo-herbácea.

A amostragem foi realizada em julho de 1996 e dois locais com grande concentração de indivíduos de C. macrophyllus foram escolhidos ao longo da borda das trilhas. Em cada um destes locais, duas parcelas de $5 \times 5 \mathrm{~m}\left(25 \mathrm{~m}^{2}\right)$ foram delimitadas, totalizando quatro parcelas nas duas áreas.

Nas parcelas, foram amostradas todas as plantas com ramos de altura igual ou superior a $13 \mathrm{~cm}$. Cada ramo foi amostrado como um forófito distinto e tomados os seguintes parâmetros: altura, número total de folhas e número de folhas com epifilo. Quando em número suficiente, foram coletadas seis folhas de cada forófito, duas da base, duas do ápice e duas da porção mediana. As folhas coletadas foram prensadas e secas em estufa para posterior cálculo da área foliar e separação das espécies epifílicas.

As espécies do epifilo foram inicialmente separadas como morfoespécies. Amostras representativas foram separadas com tesoura e incluídas na coleção de criptógamas do Herbário do Departamento de Botânica do Instituto de Ciências Biológicas da Universidade Federal de Minas Gerais (BHCB). Os líquens, briófitas e algas não liquenizadas das mesmas amostras foram enviados para identificação por especialista. Líquens mortos não foram identificados até espécie, sendo incluídos em apenas uma categoria.

Para o cálculo da área foliar média, 71 folhas foram aleatoriamente escolhidas dentre aquelas amostradas nas duas trilhas e suas áreas foram estimadas através do peso seco de $1 \mathrm{~cm}^{2}$ de folha.

A comparação entre as amostras das duas áreas do PERD foi efetuada através do teste t de Student (Brower \& Zar 1977).

\section{Resultados e Discussão}

$\mathrm{Na}$ trilha da Campolina, foram amostrados 78 forófitos de C. macrophyllus e, na do Vinhático, 68.

As espécies epifílicas encontradas em $C$. macrophyllus nas duas trilhas do PERD totalizaram 14 espécies incluindo: 11 líquens, uma alga (Phycopeltis sp.), uma hepática (Lejeuneaceae) e um fungo (tabela 1). 


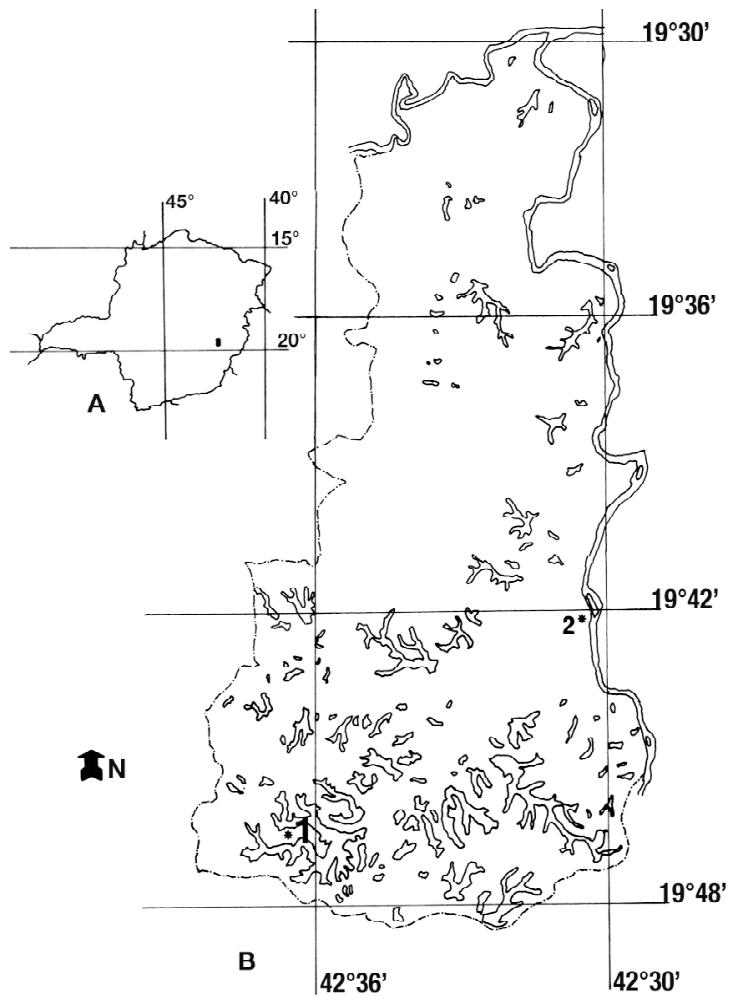

Figura 1. Localização do Parque Estadual do Rio Doce no estado de Minas Gerais (A) e localização das trilhas amostradas dentro dos limites do Parque (B). 1 = Vinhático, 2 = Campolina.
É nítida a predominância dos líquens nas duas áreas, sendo $81,8 \%$ das espécies na trilha da Campolina e $72,7 \%$ na trilha do Vinhático, enquanto que alga e fungo juntos totalizam $18,2 \%$ das espécies na Campolina e alga, hepática e fungo constituem 27,3\% das espécies no Vinhático.

Na trilha da Campolina, foram encontradas três espécies que não ocorreram na trilha do Vinhático (Porina octomera, P. tetramera e Strigula phyllogena), enquanto outras três foram encontradas apenas na trilha do Vinhático (Gyalideopsis vulgaris, Porina mirabilis e uma Lejeuneaceae). Foram encontradas oito espécies comuns às duas trilhas amostradas.

A espécie mais abundante em C. macrophyllus foi Porina epiphylla, que ocorreu em $80,8 \%$ das folhas da base nos forófitos da Campolina e em 97\% nas do Vinhático. Porina rubentior e Microtheliopsis uleana foram as segunda e terceira espécies mais abundantes, representadas em $80,6 \%$ das folhas da base e $56,7 \%$ das folhas medianas no Vinhático, e em $35,9 \%$ das folhas da base e $37,2 \%$ das folhas medianas na Campolina, respectivamente (tabela 1). A categoria dos líquens mortos vem a seguir com presença em 33,3\% das folhas da base nos forófitos da Campolina e 47,8\% das folhas medianas na do Vinhático.

Tabela 1. Organismos epifílicos em Conchocarpus macrophyllus amostrados nas trilhas da Campolina e do Vinhático, Parque Estadual do Rio Doce, MG. ( $\mathrm{n}$ = número de forófitos com espécies epifílicas).

\begin{tabular}{|c|c|c|c|c|c|c|c|c|c|c|c|c|}
\hline \multirow{3}{*}{ Táxon } & \multicolumn{6}{|c|}{ Campolina } & \multicolumn{6}{|c|}{ Vinhático } \\
\hline & \multicolumn{2}{|c|}{$\begin{array}{l}\text { folhas } \\
\text { do ápice }\end{array}$} & \multicolumn{2}{|c|}{$\begin{array}{l}\text { folhas } \\
\text { medianas }\end{array}$} & \multicolumn{2}{|c|}{$\begin{array}{l}\text { folhas } \\
\text { da base }\end{array}$} & \multicolumn{2}{|c|}{$\begin{array}{l}\text { folhas } \\
\text { do ápice }\end{array}$} & \multicolumn{2}{|c|}{$\begin{array}{l}\text { folhas } \\
\text { medianas }\end{array}$} & \multicolumn{2}{|c|}{$\begin{array}{l}\text { folhas } \\
\text { da base }\end{array}$} \\
\hline & $\mathrm{n}$ & $\%$ & $\mathrm{n}$ & $\%$ & $\mathrm{n}$ & $\%$ & $\mathrm{n}$ & $\%$ & $\mathrm{n}$ & $\%$ & $\mathrm{n}$ & $\%$ \\
\hline \multicolumn{13}{|l|}{ Gyalideopsis vulgaris (Müll. } \\
\hline Arg.) Lücking & 0 & 0 & 0 & 0 & 0 & 0 & 0 & 0 & 20 & 29,9 & 4 & 6 \\
\hline Mazosia rotula (Mont.) A. Massal. & 0 & 0 & 4 & 5,1 & 2 & 2,6 & 1 & 1,5 & 13 & 19,4 & 1 & 1,5 \\
\hline Microtheliopsis uleana Müll. Arg. & 17 & 21,8 & 29 & 37,2 & 17 & 21,8 & 9 & 13,4 & 38 & 56,7 & 34 & 50,7 \\
\hline Porina epiphylla (Fée) Fée s. 1. & 12 & 15,4 & 58 & 74,4 & 63 & 80,8 & 6 & 9 & 55 & 82,1 & 65 & 97 \\
\hline P. mirabilis Lücking \& Vezda & 0 & 0 & 0 & 0 & 0 & 0 & 0 & 0 & 1 & 1,5 & 0 & 0 \\
\hline P. octomera (Müll. Arg.) F. Schill. & 0 & 0 & 6 & 7,7 & 9 & 11,5 & 0 & 0 & 0 & 0 & 0 & 0 \\
\hline P. rubentior (Stirt.) Müll. Arg. & 5 & 6,4 & 25 & 32,1 & 28 & 35,9 & 5 & 7,5 & 41 & 61,2 & 54 & 80,6 \\
\hline P. tetracerae (Afzel.) Müll. Arg. & 1 & 1,3 & 0 & 0 & 2 & 2,6 & 0 & 0 & 4 & 6 & 2 & 3 \\
\hline P. tetramera (Malme) R. Sant. & 0 & 0 & 0 & 0 & 1 & 1,3 & 0 & 0 & 0 & 0 & 0 & 0 \\
\hline \multicolumn{13}{|l|}{ Strigula phyllogena (Müll. Arg.) } \\
\hline R. C. Harris & 0 & 0 & 1 & 1,3 & 0 & 0 & 0 & 0 & 0 & 0 & 0 & 0 \\
\hline S. subtilissima (Fée) Müll. Arg. & 0 & 0 & 5 & 6,4 & 6 & 7,7 & 0 & 0 & 4 & 6 & 7 & 10,4 \\
\hline Líquens mortos & 22 & 28,2 & 22 & 28,2 & 26 & 33,3 & 1 & 1,5 & 32 & 47,8 & 12 & 17,9 \\
\hline Phycopeltis sp. & 1 & 1,3 & 1 & 1,3 & 0 & 0 & 0 & 0 & 1 & 1,5 & 0 & 0 \\
\hline Lejeuneaceae & 0 & 0 & 0 & 0 & 0 & 0 & 0 & 0 & 2 & 3 & 2 & 3 \\
\hline Fungo & 3 & 3,8 & 10 & 12,8 & 17 & 21,8 & 0 & 0 & 12 & 17,9 & 11 & 16,4 \\
\hline
\end{tabular}


Fatores microambientais estão provavelmente interferindo na composição do epifilo encontrado em C. macrophyllus. As espécies P. epiphylla, $P$. mirabilis, P. octomera, M. uleana, S. subtilissima e M. rotula são listadas por Lücking (1997b) como típicas de florestas fechadas ou parcialmente abertas, primárias ou secundárias antigas, enquanto que P. tetramera possuiria ampla tolerância ao ambiente, ocorrendo desde florestas primárias até vegetação exposta. Apenas a presença de $P$. rubentior na trilha do Vinhático, uma área que sofreu ação do fogo há cerca de 30 anos, é considerada digna de nota, pois Lücking (1997b) cita-a como típica de floresta primária, não tendo sido encontrada até agora em matas secundárias, mesmo naquelas antigas.

$\mathrm{Na}$ trilha da Campolina, 30 (38,5\%) forófitos apresentaram cobertura pelo epifilo nas folhas do ápice, medianas e da base, $34(43,6 \%)$ nas folhas medianas e da base, dois $(2,6 \%)$ só nas folhas do ápice, dois $(2,6 \%)$ só nas folhas medianas, nove $(11,5 \%)$ só nas folhas da base e um $(1,2 \%)$ não apresentou epifilo. No Vinhático, 10 (14,7\%) forófitos apresentaram cobertura pelo epifilo nas folhas do ápice, medianas e da base, 48 (70,6\%) nas folhas medianas e da base, nenhum só nas folhas do ápice ou medianas, oito $(11,8 \%)$ só nas folhas da base e dois $(2,9 \%)$ não apresentaram epifilo. Os números foram significativamente diferentes entre as duas áreas ( $\mathrm{t}=16,2, \alpha=0,05, \mathrm{DF}=5$, figura 2 ).

Diferenças entre o grau de cobertura epifílica nas folhas das plantas na Campolina e no Vinhático talvez sejam devido a taxas distintas de produção e crescimento foliar entre os indivíduos das duas áreas.

É provável que C. macrophyllus tenha crescimento foliar lento e que suas folhas tenham um período de vida longo, o que é sugerido não só pela presença de epifilo nas lâminas foliares como também pelo grau de esclerofilia. Apenas um estudo a longo prazo, com acompanhamento do desenvolvimento das folhas de C. macrophyllus nas duas áreas, permitiria avaliar as possíveis diferenças no grau de cobertura e na composição do epifilo, uma vez que o número de espécies aumenta com a idade e decresce até pouco antes da queda das folhas (Lücking 1995).

$\mathrm{Na}$ Campolina, 17 forófitos apresentaram 100\% de suas folhas cobertas por epifilo, enquanto que no Vinhático apenas três tiveram o mesmo percentual de cobertura.
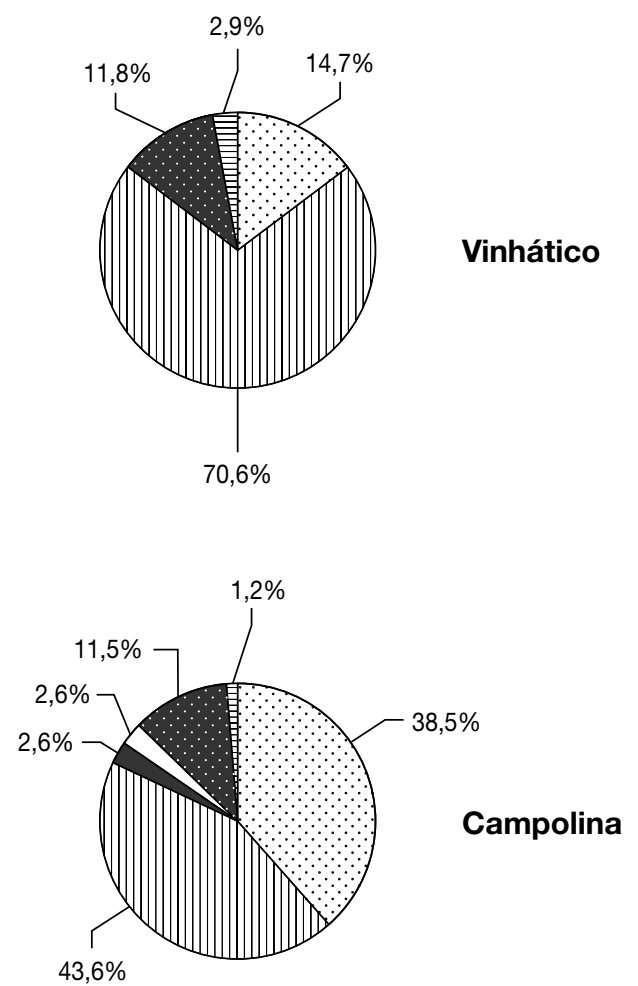

Figura 2. Número e porcentagem de forófitos coletados na trilha do Vinhático $(\mathrm{N}=68)$ e da Campolina $(\mathrm{N}=78)$, com cobertura epifílica nas folhas do ápice, medianas e da base ( $\because$ ), medianas e da base $(\mathbb{\square})$, só do ápice $(\square)$, só medianas $(\square)$, só da base ( $\mathbf{1})$, ou sem epifilo (烏.

A altura dos forófitos amostrados na Campolina variou de 13 a $155 \mathrm{~cm}(\mathrm{x}=41,8 \mathrm{~cm})$ e no Vinhático de 13 a $230 \mathrm{~cm}(\mathrm{x}=77,8 \mathrm{~cm})$, significativamente diferentes $(t=9,6, \alpha=0,05, D F=144)$. Talvez a altura maior dos forófitos na trilha do Vinhático se deva à maior penetração de luz nessa trilha e a conseqüente taxa mais elevada de fotossíntese.

$\mathrm{Na}$ Campolina, a área foliar das folhas amostradas variou de 26,1 a $205,9 \mathrm{~cm}^{2}\left(\mathrm{x}=90,7 \mathrm{~cm}^{2}\right)$, enquanto que no Vinhático variou de 19,8 a $189 \mathrm{~cm}^{2}$ $\left(\mathrm{x}=84,2 \mathrm{~cm}^{2}\right)$, não apresentando diferenças significativas $(t=0,41, \alpha=0,05, D F=140)$.

$\mathrm{Na}$ Campolina, o número de folhas por forófito variou de três a $30(\mathrm{x}=13,9)$ e no Vinhático de quatro a $38(\mathrm{x}=15,5)$, não apresentando diferenças significativas $(\mathrm{t}=0,63, \alpha=0,05, \mathrm{DF}=144)$. $\mathrm{Na}$ Campolina, o número de folhas com epifilo por forófito variou de zero a $24(\mathrm{x}=9,8)$, enquanto 
que no Vinhático variou de zero a $34(\mathrm{x}=11,8)$, significativamente diferentes $(\mathrm{t}=10,63, \alpha=0,05$, $\mathrm{DF}=144)$.

Apesar de não haver diferenças significativas entre a composição específica da flora epifílica entre as duas áreas, o maior número de folhas com epifilo por forófito pode ser um indicador de perturbação na trilha do Vinhático, que sofreu ação do fogo em época mais recente. A maior penetração de luz nas clareiras e aberturas na mata perturbada pode ter otimizado o crescimento dos organismos epifílicos e a colonização das folhas, assim como o crescimento em altura dos forófitos.

O estudo da diversidade dos organismos epifílicos pode ser de grande interesse no aspecto de bioindicação, assim como estudos enfocando organismos pouco estudados são necessários para se avaliar seu papel nas interações ecológicas (During \& van Tooren 1990) e na ciclagem de nutrientes (Bentley \& Carpenter 1984).

Agradecimentos - Agradecemos ao Dr. Robert Lücking pela identificação dos líquens, alga e hepática, à Dra. C. Jacobi pela leitura e correção do Abstract e ao Instituto Estadual de Florestas (IEF) pela realização deste estudo nos limites do Parque Estadual do Rio Doce.

\section{Referências bibliográficas}

ANDREOLI, C. \& PAOLETTI, M.G. 1993. Epiphyllous algae on the foliage of rain forest Bromeliaceae in Ecuador. Tropical Zoology 1:1-6

BENTLEY, B.L. \& CARPENTER, E.J. 1984. Direct transfer of newly-fixed nitrogen from free-living epiphyllous microorganisms to their host plant. Oecologia 63:52-56.

BENZING, D.H. 1990. Vascular epiphytes. Cambridge University Press, Cambridge.
BROWER, J.E. \& ZAR, J.H. 1977. Field \& laboratory methods for general ecology. 2a ed. Wm. C. Brown Publishers, Dubuque.

BRUCK, E.C., FREIRE, A.M.V. \& LIMA, M.F. 1995. Unidades de conservação no Brasil. Cadastramento e vegetação 19911994. Instituto Brasileiro do Meio Ambiente e dos Recursos Naturais Renováveis, Brasília.

CETEC. 1981. Vegetação do Parque Estadual do Rio Doce. In Programa de Pesquisas Ecológicas no Parque Estadual do Rio Doce. v.2, Fundação Centro Tecnológico de Minas Gerais, Belo Horizonte.

DURING, H.J. \& VAN TOOREN, B.F. 1990. Bryophyte interactions with other plants. Botanical Journal of the Linnean Society 104:79-98.

IBGE. 1992. Manual técnico da vegetação brasileira. Fundação Instituto Brasileiro de Geografia e Estatística, Rio de Janeiro.

LESSICA, P., MCCUNE, B., COOPER, S.V. \& HONG, W.S. 1991. Differences in lichen and bryophyte communities between old-growth and managed second-growth forest in Swan Valley, Montana. Canadian Journal of Botany 69:17451755 .

LÜCKING, R. 1995. Biodiversity and conservation of foliicolous lichens in Costa Rica. Mitteilungen der Eidgenössischen Forschungsanstalt für Wald, Schnee und Landschaft 70:63-92.

LÜCKING, R. 1997a. Estado actual de las investigaciones sobre líquenes foliícolas en la región Neotrópica, com un análisis biogeográfico preliminar. Tropical Bryology 13:87-114.

LÜCKING, R. 1997b. The use of foliicolous lichens as bioindicators in the tropics, with special reference to the microclimate. Növenyrendszertani és Novényföldrajzi Tanszék. Eötvös Loránd Tudományegyetem 21:99-116.

ROGERS, R.W. 1989. Colonization, growth, and survival strategies of lichens on leaves in a subtropical rainforest. Australian Journal of Ecology 14:327-333.

SILVA JR, M.C., SCARANO, F.R. \& CARDEL, F.S. 1995. Regeneration of an Atlantic forest formation in the understorey of a Eucalyptus grandis plantation in Southeastern Brazil. Journal of Tropical Ecology 11:147-152.

WOLF, J.H.D. 1994. Factors controlling the distribution of vascular and non-vascular epiphytes in the northern Andes. Vegetatio 112:15-28. 